\title{
Antenatal Health Care Services and Degree of Clients' Satisfaction in Sharkia Governorate, Egypt
}

Yasmin H. Hussein ${ }^{1}$, Hanaa S. Said ${ }^{1}$

${ }^{1}$ Department of Family Medicine, Faculty of Medicine, Zagazig University, Egypt

Abstract:

Background: client's satisfaction is a measure of the extent to which clients are trustworthy with the health care which they received. Pregnant women's satisfaction is considered a performance indicator in antenatal care (ANC) quality evaluation. Objectives: To assess clients' satisfaction regarding antenatal health care services provided at the primary health care level in Sharkia governorates, Egypt.

Methods: a cross-sectional study was conducted on 765 pregnant women. Through a multistage cluster sampling technique, four health facilities were selected to represent Sharkia governorate. Participants' data regarding socio-demographic characteristics, numbers of their antenatal visits and questions to assess the satisfaction about the quality of antenatal care were collected via semistructured questionnaire.

Results: The study revealed that out of the total participants, overall satisfied with ANC services were $288(37.6 \%)$. The most common specific component of ANC that had good-satisfaction by the respondents was tetanus vaccine availability $(100 \%)$. Shortage of referral requirements were the commonest causes of dissatisfaction. Clients who were urban residents, who had middle \& high social class and who have $\geq 2$ previous antenatal care visits were more likely to have the satisfaction in ANC services.

Conclusion: The results of the study reflect multiple pitfalls in the different components of the ANC services, so special attention must be given for increasing resources to improve the quality of ANC services in the governorate.

Keywords: Dissatisfaction, referral, tetanus, women.

\section{Introduction:}

To improve service delivery in primary health care units, there is a need to place a high priority on the clients and their level of satisfaction with the provided services. ${ }^{(1)}$

Patient satisfaction should be taken as a serious measurement by health experts and governments due to: satisfaction is a predictor of patient's compliance with their treatment and health provider's recommendations, assessing the success of delivering information to patients; also patient satisfaction has a great role in quality assurance and continuous quality improvement systems. $^{(2)}$ Lastly improving patient satisfaction associated with higher utilization rate to health services and better health outcome. (3)

Population's health can be affected by four headings: heredity, environment, lifestyle, and healthcare service. Public health services are provided through a nation-wide network which is established based on primary health care (PHC) system..$^{(\mathbf{1})}$ Primary care is known as the basic level of health care and is the first contact for the patient before further disease management can be done. ${ }^{(4)}$ 
Maternal health is related not only to the health of a woman but also has a direct bearing on the health of her newborn. Every day in 2015 about 830 women die from pregnancy- or childbirth-related complications around the world. Most of these deaths occurred in low-resource settings, and most could be prevented. $99 \%$ of all maternal deaths occur in developing countries. ${ }^{(5)}$

Attendance at antenatal clinics and receipt of professional perinatal care are associated with a reduction in maternal deaths. Antenatal care (ANC) reduces maternal and perinatal morbidity and mortality directly through the early detection and treatment of pregnancyrelated illnesses, and indirectly through the identification of women who are at increased risk of complications during childbirth. ${ }^{(6)}$

The global maternal mortality ratio declined by $2.3 \%$ per year between 1990 and 2015 ;(5) $^{(5)}$ and according to the Egyptian demographic and health survey (DHS), maternal mortality ratio declined from 62 per 100000 in 2008 to 45 per 100000 in 2014. The improvement in maternal mortality can be attributed to several factors including access to primary care and increased rates of regular antenatal care (ANC) $(83 \%$ in 2014) which is the most important factors. ${ }^{(7)}$
The Egyptian DHS, $2015^{\text {(7) }}$ demonstrates that antenatal coverage regarding the source for antenatal care was $80 \%$ to private medical sector versus only $14.4 \%$ to the public medical sector (including 2.5\% to urban health units and $8.1 \%$ to rural health units). Lack of use of public health services is questionable?

The study was conducted to assess clients' satisfaction regarding antenatal health care services provided at the primary health care level in Sharkia governorates, Egypt.

Methods:

\section{Study design and sampling method:}

A cross-sectional study was conducted. The sample was calculated to be 765 pregnant women based on women satisfaction with antenatal health services prevalence in Egypt $53.6 \%,{ }^{(8)}$ and the total number of married females and in the childbearing period was 1,866,000 according to Egyptian health and demographic survey, 2014, using an online open epi program at $95 \%$ confidence interval and 5\% confidence limit and design effect of 2. Through a multistage cluster sampling technique, Zagazig and Belbeis health districts were selected due to the highest population number regarding census 2017, (9) to represent Sharkia governorate which administratively divided into 19 health districts. ${ }^{(10)}$ 
Zagazig health district includes only one urban health center and (31) rural health units, two health facilities were selected randomly to represent rural and urban residences. In the same way, two health facilities were selected randomly to represent rural and urban residences in Belbeis health district (which includes one urban health center and (33) rural units). So, four health facilities were selected to represent Sharkia governorate.

Sample units were divided and collected from the selected health facilities by proportional allocation method.

\section{Study participants and data collection:}

The study included pregnant women attending health facilities asking for full antenatal care or tetanus vaccine only; women were interviewed using a semi-structured questionnaire according to a previous study done in Egypt. (11) The questionnaire consisted of socio-demographic assessment questions, (12) and questions about duration of pregnancy, number of their antenatal visit and number of their children, others to assess the satisfaction about quality of antenatal care as accessibility, waiting time, referral, cleanness, privacy, performance of physician and the staff.

Administrative approval: The study was approved by Sharkia health directorate. An official permission letter was obtained from the authority and directed to health districts and health facilities included in the study.

Ethical approval: Ethical considerations were taken through the whole study including fully informed participants with the purpose and nature of the study and then oral consent was taken from participants. Coded numbers for each participant was used to guarantee privacy. Official approval from the Institutional review board (IRB) was taken (ZU-IRB \#5359)

Statistical analysis: Data were analyzed using the Statistical Package for Social sciences (SPSS) software (Statistical Package for the Sociable Sciences, version 20, SPSS Inc. Chicago, IL, USA).

Qualitative data were expressed as number and percentage and analyzed by using the Chisquare test $\left(\mathrm{X}^{2}\right)$ to detect the relation between different qualitative variables. Quantitative data were expressed as mean $\pm \mathrm{SD}$.

\section{Results:}

Regarding socio-demographic characteristics, more than half of the pregnant women participated in the current study were urban residents, aged $\geq 29$ years old, housewives and almost half of them had a medium social class. About (33\%) of them had got education below secondary education. More than half of the women interviewed were pregnant for less than 
20W and attended for the first visit. About $(35 \%)$ of them had one child (Table 1).

The study revealed that out of the total clients, overall satisfied with ANC were 288 (37.6\%) (Figure 1). Clients who were urban residents were about 6 times more likely $(\mathrm{OR}=6.81 ; 95 \%$ CI, 4.89-9.46; p-value $=0.000)$ to be satisfied with ANC services as compared to those were rural residents. Also, who had middle \& high social class was about 2 times more likely $(\mathrm{OR}=6.81 ; 95 \% \quad \mathrm{CI}, 4.89-9.46 ;$ p-value $=$ 0.000) to be satisfied with ANC services as compared to those had low social class. However, the study revealed no significant association between satisfied and not-satisfied groups as regard education and occupation (Table 2).

Women who have $\geq 2$ previous antenatal care visits were about 7 times more likely $(\mathrm{OR}=6.81$; 95\% CI, 4.89-9.46; p-value $=0.000)$ to be satisfied with ANC services as compared to those with $\leq 1$ visit (Table 2).

Regarding the degree of satisfaction about the different components of the antenatal care services, Table (3) showed the satisfaction about accessibility; more than half of clients were satisfied with the center's location, the availability of transport methods to reach the center, the waiting time before examination and the waiting time for laboratory results $(60.3 \%$,
$62.2 \%, \quad 56.1 \%$, and $59.1 \%$ respectively). However, about half of them (42\%) were not satisfied with the hours of work.

About half of females were satisfied by the cleanness of the center (45\%) and the waiting place $(48.6 \%)$. Satisfaction regarding the performance of physician team in the center showed that $(71.6 \%)$ of the clients were satisfied as regard explanation of the results of investigations followed by an explanation of the rationale of investigations (69.7\%). Nearly equal rates of satisfaction reported for the examination time $(61.7 \%)$, explanation of their problem (57\%), taking a medical history (55.9\%), answering questions (52.3\%) and trust their doctor (50.7\%) (Table 3).

The satisfaction with the performance of nurses and other center staff showed that most of the clients $(71.6 \%)$ were satisfied with the pattern of staff management (dealing politely and professionally), $56.1 \%$ of patients were satisfied with delivering information and providing help. Regarding feeling privacy in the examination room only $(23.5 \%)$ feel privacy while $(46.7 \%)$ to some extent (Table 3).

Regarding drug availability and laboratory services, $100 \%$ of the clients were satisfied by tetanus vaccine availability and the majority of them were satisfied by iron, folic acid $(80.1 \%)$ and the chronic diseases' drugs availability 
(75.4\%). While near half of them were satisfied by essential laboratory investigations (47.2\%) and US availability (39.9\%). The majority of women were satisfied with the cost of the different provided services (Table 3).

Degree of satisfaction regarding health education sessions, Table (4) showed that about half of the clients $(49.2 \%)$ were not satisfied with physician explanation of advantages of ANC. Satisfaction of women regarding orientation about pregnancy care showed that the majority of the clients were not satisfied with explanation of physician about teeth care $(87.5 \%)$ and safe effort (70.1\%) during pregnancy, more than half of them were not satisfied with the information they received regarding basics of newborn care $(63.9 \%)$. Near half of the clients were not satisfied with the information provided about nutrition, explanation of measures of personal hygiene, physician explanation about breast care during pregnancy and the importance of breastfeeding, follow up appointment, allowable medication and fetal movement follow up.

The satisfaction of females towards the knowledge provided by the physician about late pregnancy period showed that about $(40.8 \%)$ were not satisfied with the information provided by the physician about signs of labor and
(34.5\%) were not satisfied with the explanation of the risks of labor. (Table 4)

Regarding satisfaction about the referral system in the center (Table 4), 100\% of the clients were not satisfied by ambulance unavailability, the physician help in admission and the follow-up care. Half of the clients were not satisfied with not giving a referral report. However, about half of the clients were satisfied to some extent with first aid management (55\%) and physician explanation of the cause of referral $(45 \%)$.

The main recommendations were reported by the clients included in the study for improving their satisfaction about ANC services were increase resources (33\%) followed by increase working hours (17\%) (Figure 2).

\section{Discussion:}

Pregnancy is a very important and special event from both social and medical point of view. Maternal satisfaction to Antenatal Care (ANC) Services has been linked to the quality of the provided services and the extent to which specific maternal needs are met. ${ }^{(13)}$ The result of the current study revealed that $37.6 \%$ of women were satisfied with the ANC services they received. This is almost near the results of a previous Egyptian study reported that women satisfaction with antenatal health services prevalence in Egypt is $53.6 \%{ }^{(8)} \mathrm{A}$ higher finding (68\%) was reported by a study 
conducted in Oman. ${ }^{(14)}$ Many studies revealed that satisfaction of clients to ANC services varied from country to country. ${ }^{(15)}$

Women satisfied with ANC services was significantly associated with frequent (>1times) previous ANC visits that women had. This was directly linked to the results of a study conducted in Oman, (16) and a study conducted in Ethiopia, (13) in which patient satisfaction was significantly higher among women in the highest visit groups. This positive association could be due to developing awareness on its importance by repeated visiting, increasing client need and effective response to this need by the health care workers.

In this study, having satisfied to ANC services was significantly associated with respondents who had middle and high social class. This disagrees with previous studies, in that better satisfaction observed in groups had lower social class. ${ }^{(17,18)}$ One possible explanation for this may be most of the Egyptian women with middle and high social class utilize the public medical sector for tetanus toxoid vaccination only and have no contact with the other components of the ANC services unlike low social class women. This supports the results stated by the Egyptian DHS, 2014 which demonstrates that antenatal coverage regarding the source for antenatal care was $80 \%$ to private medical sector versus only $14.4 \%$ to the public medical sector.

Regarding residence, this study reported that urban residents were significantly more satisfied with ANC services. This was in line with the previous study found that utilization and satisfaction with the ANC services are much more in urban residents than in rural residents. ${ }^{(19)}$ This gap can be explained by differences between the urban and rural areas in knowledge, attitude and practices of women towards ANC also better resources and equipment in the urban health centers.

The study results show that more than half of the clients were satisfied with the center's location, the availability of transport methods to reach the center $(60.3 \%$ and $62.2 \%$ respectively). This was in concordance with a study conducted in Ethiopia which reported the percentage of satisfaction of about $50 \%$. (13)

Regarding waiting time more than half of the women included in the current study were satisfied. Reducing waiting time was an important aspect for improving ANC services and it was more important than increasing consultation time. ${ }^{(20)}$

The current study revealed that near half of the clients were not satisfied with the hours of work 
and $17 \%$ from them recommended increasing working hours to improve their satisfaction with ANC services. The same finding reported by a study conducted in Ethiopia. ${ }^{(13)}$

Cleanliness and maintenance of hygiene were reported as determinants of satisfaction in many studies in developing countries. ${ }^{(21)}$ The current study found that about half of females were satisfied by the cleanness of the center and the waiting place and $7.8 \%$ from them recommended improving cleaning to increase their satisfaction.

Communication by providers with the women during ANC visits plays an important role in their satisfaction with care and the perceived neglect in care, including delay in attending to the client, not involving the client in care and mistakes in investigations results adversely affected satisfaction with services. ${ }^{(22)}$ The current study found that most of the clients were satisfied by the physicians' performance. This was in concordance with the results of an Egyptian study. ${ }^{(11)}$

Regarding the satisfaction with the performance of nurses and other centers' staff showed that more than half of the clients were satisfied. This agreed with the results of a study conducted in Oman reported that the positive behavior of the health staff and the warm reception of the clients were the most satisfying parts of the ANC services. ${ }^{(14)}$

Privacy is a key requirement of women utilizing ANC services, for physical examinations. This study reported low satisfaction of the clients towards the privacy in the examination room. This was in concordance with the results of another study found that inadequate privacy during antenatal checkup and counseling was associated with women's poor satisfaction of services. ${ }^{(23)}$ Regarding drug availability the current study found that the majority of the clients were satisfied, however, the half of them were satisfied by essential laboratory investigations and US availability and $33.5 \%$ from them recommended increasing these resources to improve their satisfaction. Availability of prescription drugs and essential equipment were reported as significant predictors of satisfaction with ANC services in many developing countries. ${ }^{(24)}$

This study found that the majority of women were satisfied with the cost of the different provided services. Significant associations between cost and maternal satisfaction and the utilization of ANC services were found in a previous Egyptian study. ${ }^{(25)}$

One of the main goals of ANC services is providing adequate information that is important 
for improving pregnancy outcomes. The current study revealed a low level of satisfaction towards all components of the health education sessions. These results can be explained by the lack of doctors' training about how to communicate properly with their patients this is a key point to improve the quality of care and the client satisfaction as revealed by a study conducted in Iran which found that one of the key reasons for satisfaction with group ANC was the information provided to the clients through the health education sessions. ${ }^{(26)}$

Regarding satisfaction about the referral system in the center, the current study found a low level of satisfaction towards all components of the referral system and $10.5 \%$ from the clients recommended ambulance availability to improve their satisfaction. A study conducted in Nigeria revealed that the absence of prompt referral was a cause for dissatisfaction with ANC services (27)

\section{Conclusion:}

The most common component of ANC that had good-satisfaction by the respondents was tetanus vaccine availability (100\%). The most common health education component during ANC services, which was satisfied by the respondents was "the importance of breastfeeding". Shortage of referral requirements were the commonest causes of dissatisfaction. Women had $\geq 2$ previous ANC visits, urban residents and had middle and high social classes were more satisfied.

\section{Recommendations:}

Special attention must be given for increasing resources to improve all components of ANC services in the governorate. Providers must replan and improve their performances for another highest satisfaction in the future. First time ANC visitors should be given more attention by providers to increase the chance for a return visit.

Study limitation: Lack of cooperation from some women but the researchers persuaded them to participate in the study after explanation of the study importance, objectives and methodology.

Authors' contribution: $\mathrm{YHHH}$ contributed to the planning of the work, drafting of the work, statistical analysis, reporting, revision of the manuscript, approval of the final version of the manuscript, and agreed to all aspects of the work. HSSE contributed to planning of the work, drafting of the work, literature review, data collection, revision of the manuscript, approval of the final version of the manuscript, and agreed to all aspects of the work. 
Conflict of interests: There are no known conflicts of interest associated with this publication.

Funding: There has been no financial support for this work that could have influenced its outcome.

Acknowledgment: The authors would like to thank the participants and the selected health facilities' staff for their help to accomplish this work.

\section{References:}

1- Zara A, Taheri 1, Jahromi MK. Clients' Satisfaction with Primary Health Care in Jahrom: A Cross-Sectional Study on Iranian Health Centers Int.J.Curr.Microbiol.App.Sci.2015.4(3): 84-89

2- Hasan A. Patients Satisfaction with Maternal and Child Health Services Among Mothers Attending the Maternal and Child Health Training Institute in Dhaka, Bangladesh (Doctoral dissertation, Mahidol University).2007

3- Banka G, Edgington S, Kyulo $\mathrm{N}$ et al. Improving patient satisfaction through physician education, feedback, and incentives. J Hosp Med. 2015 Aug; 10(8):497-502.

4- Azhar A, Rahman MM, Arif MT. Satisfaction on primary health care services in Sarawak, Malaysia: evidence from a cross-sectional community based study. Malaysian Journal of Public Health Medicine.2016; 16:3.

5- Maternal mortality.Who.int. 2018 [accessed April 2018]. Available from: https://www.who.int/en/news-room/factsheets/detail/maternal-mortality

6- Dawood MM, Bin-Berik AS, Sayad A et al. Utilisation of Reproductive Health Services by Women in Mukalla City, Yemen. J Public Health Dev Ctries. 2015; 1(1): 22-30.

7- El-Zanaty F. and Associates [Egypt], and ICF International. 2015. Ministry of Health and Population [Egypt], Egypt Demographic and Health Survey 2014. Cairo, Egypt and Rockville, Maryland, USA: Ministry of Health and Population and ICF International. Available from: https://dhsprogram.com/what-wedo/survey/survey-display-397.cfm

8- Soliman FE. Satisfaction of rural pregnant women as quality indicator of provided antenatal care. IJSRP. 2015 Mar; 5(3).

9- Capmas.gov.eg. 2017 [accessed July 2018]. Available from: http://www.capmas.gov.eg/Pages/StaticP ages.aspx?page $\mathrm{id}=7188$ 
10-Sharkia.gov.eg. 2017 [accessed July 2018].

Available

from:

http://www.sharkia.gov.eg/Division/defa $\underline{\text { ult.aspx }}$

11-Montasser NA, Helal RM, Megahed WM et al. Egyptian women's satisfaction and perception of antenatal care. Int J Trop Dis Health. 2012 Apr;2(2):145-56.

12- Fahmy SI, Nofal LM, Shehata SF et al. Updating indicators for scaling the socioeconomic level of families for health research. J Egypt Public Health Assoc. 2015 Mar 1; 90(1):1-7.

13-Lakew S, Ankala A, Jemal F. Determinants of client satisfaction to skilled antenatal care services at Southwest of Ethiopia: a cross-sectional facility based survey. BMC Pregnancy Childbirth. 2018 Dec; 18(1):479.

14- Ghobashi M, Khandekar R. Satisfaction among expectant mothers with antenatal Care Services in the Musandam Region of Oman. Sultan Qaboos Univ Med J. 2008 Nov; 8(3):325-32.

15-Luyben AG, Fleming VE. Women's needs from antenatal care in three European countries. Midwifery. 2005 Sep; 21(3):212-23.
16-Kamil A, Khorshid E. Maternal perceptions of antenatal care provision at a tertiary level hospital, Riyadh. Oman Med J. 2013; 28(1):33-5.

17-Chemir F, Alemseged F, Workneh D. Satisfaction with focused antenatal care service and associated factors among pregnant women attending focused antenatal care at health centers in Jimma town, Jimma zone, South West Ethiopia; a facility based cross-sectional study triangulated with qualitative study. BMC Res

Notes.

http://wwwbiomedcentralcom/1756-

0500/ 7/164. 2014; 7:164.

18-Rahman MM, Ngadan DP, Arif MT. Factors affecting satisfaction on antenatal care services in Sarawak, Malaysia: evidence from a crosssectional study. Springerplus. 2016 Jun; 5(1):725.

19- Tran TK, Gottvall K, Nguyen HD et al . Factors associated with antenatal care adequacy in rural and urban contextsresults from two health and demographic surveillance sites in Vietnam. BMC Health Serv Res. 2012 Feb; 12(1):40.

20-Srivastava A, Avan BI, Rajbangshi P et al. Determinants of women's satisfaction with maternal health care: a review of 
literature from developing countries.

BMC Pregnancy Childbirth. 2015 Apr; 15(1):97.

21-Simbar M, Ghafari F, Zahrani ST et al. Assessment of quality of midwifery care in labour and delivery wards of selected Kordestan Medical Science University hospitals. Int J Health Care Qual Assur. 2009; 22(3):266-77.

22-Dzomeku MV. Maternal satisfaction with care during labour: A case study of the Mampong-Ashanti district hospital maternity unit in Ghana. Int $J$ Nurs Midwifery. 2011; 3:30-4.

23-Simbar M, Nahidi F, Dolatian M et al. Assessment of quality of prenatal care in Shahid Beheshti Medical Science University centers. Int $\mathrm{J}$ Health Care Qual Assur. 2012; 25(3):166-76.

24-Tetui M, Ekirapa EK, Bua J et al. Quality of Antenatal care services in eastern Uganda: implications for interventions. Pan Afr Med J. 2012; $13: 27$.
25-El-Mohimen HAA, Abd-Rabou RA, Ali HA et al. Evaluation of ANC services \& women's perception in Assiut University Hospital. Ass Univ Bull Environ Res. 2006; 9:31-40.

26- Jafari F, Eftekhar H, Mohammad K et al. Does group prenatal care affect satisfaction and prenatal care utilization in Iranian pregnant women? Iran J Public Health. 2010; 39(2):52-62.

PMID:23113007

27-Balogun OR. Patients' perception of quality of antenatal service in four selected private health facilities in Ilorin, Kwara state of Nigeria. Niger Med Pract. 2007; 51:80-4. 
Table (1): Characteristics of the studied pregnant women

\begin{tabular}{|c|c|c|}
\hline characteristics & $N(765)$ & $\%$ \\
\hline $\begin{array}{l}\text { women' age } \\
19- \\
29- \\
\text { Range }(19-40) \\
\operatorname{Mean} \pm \operatorname{SD}(28.65 \pm 4.79)\end{array}$ & $\begin{array}{l}372 \\
393\end{array}$ & $\begin{array}{l}48.6 \\
51.4\end{array}$ \\
\hline $\begin{array}{l}\text { Women' Education } \\
\text { Illiterate } \\
\text { Below secondary } \\
\text { Secondary } \\
\text { Above secondary }\end{array}$ & $\begin{array}{c}44 \\
249 \\
228 \\
244\end{array}$ & $\begin{array}{c}5.8 \\
32.5 \\
29.8 \\
31.9\end{array}$ \\
\hline $\begin{array}{l}\text { Women' Occupation } \\
\text { Not work (housewives) } \\
\text { Work }\end{array}$ & $\begin{array}{l}573 \\
192\end{array}$ & $\begin{array}{l}74.9 \\
25.1\end{array}$ \\
\hline $\begin{array}{l}\text { Residence } \\
\text { Rural } \\
\text { Urban }\end{array}$ & $\begin{array}{l}364 \\
401\end{array}$ & $\begin{array}{l}47.6 \\
52.4\end{array}$ \\
\hline $\begin{array}{l}\text { Social class } \\
\text { Low } \\
\text { Medium } \\
\text { High }\end{array}$ & $\begin{array}{l}257 \\
356 \\
152\end{array}$ & $\begin{array}{l}33.6 \\
46.5 \\
19.9\end{array}$ \\
\hline $\begin{array}{l}\text { Number of children } \\
0 \\
1 \\
2 \\
>2\end{array}$ & $\begin{array}{l}104 \\
264 \\
256 \\
141\end{array}$ & $\begin{array}{l}13.6 \\
34.5 \\
33.5 \\
18.4\end{array}$ \\
\hline $\begin{array}{l}\text { Duration of pregnancy } \\
<20 \mathrm{w} \\
\geq 20 \mathrm{w}\end{array}$ & $\begin{array}{l}397 \\
368\end{array}$ & $\begin{array}{l}51.9 \\
48.1\end{array}$ \\
\hline $\begin{array}{l}\text { Number of visits } \\
1^{\text {st }} \text { visit } \\
\text { Repeated visits }\end{array}$ & $\begin{array}{l}403 \\
362\end{array}$ & $\begin{array}{l}52.7 \\
47.3\end{array}$ \\
\hline
\end{tabular}




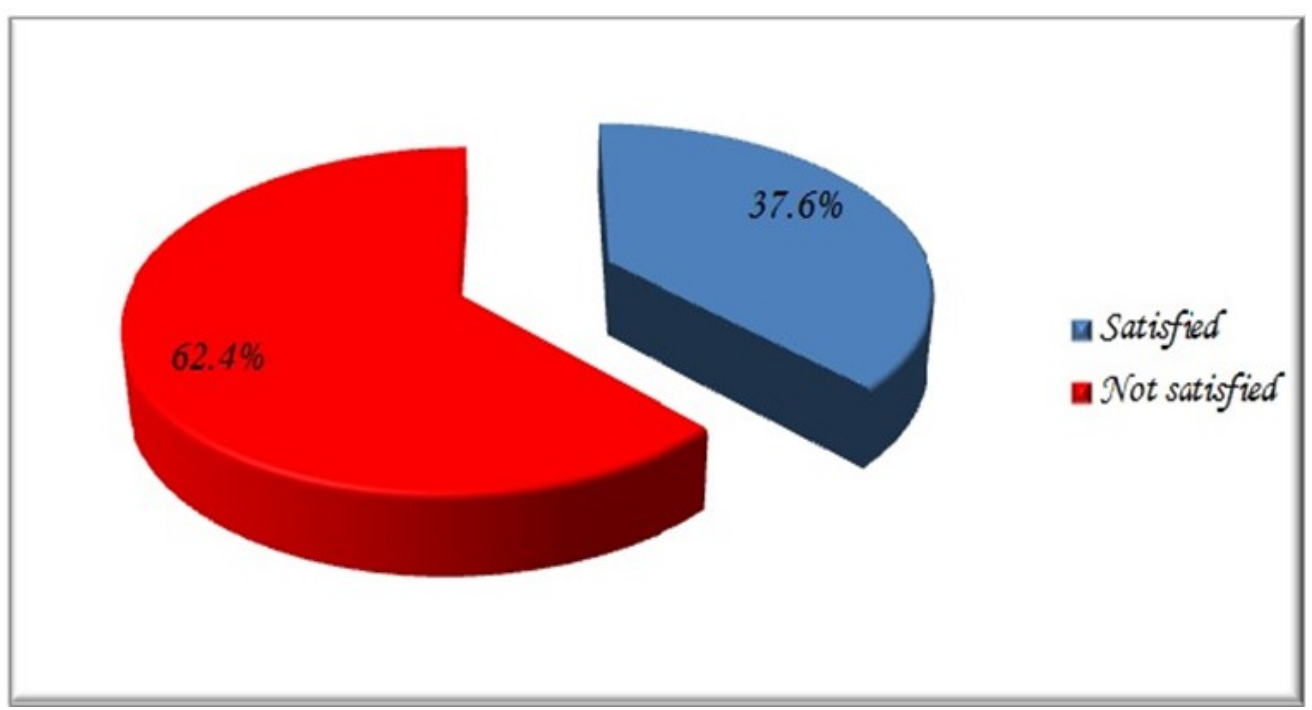

Figure (1): The studied women's overall satisfaction toward the antenatal care services 
Table (2): Comparison between satisfied and not satisfied groups as regards sociodemographic characteristics

\begin{tabular}{|c|c|c|c|c|c|c|c|c|}
\hline \multirow[t]{3}{*}{ Variable } & \multicolumn{4}{|c|}{ Maternal satisfaction } & \multirow{2}{*}{\multicolumn{2}{|c|}{ Total }} & \multirow{3}{*}{$\begin{array}{c}\text { OR* } \\
(95 \% \mathrm{CI})\end{array}$} & \multirow[t]{3}{*}{$\mathbf{p}^{* *}$} \\
\hline & \multicolumn{2}{|c|}{ Not satisfied } & \multicolumn{2}{|c|}{ Satisfied } & & & & \\
\hline & $\begin{array}{c}N \\
(477)\end{array}$ & $\%$ & $\begin{array}{c}\mathrm{N} \\
(\mathbf{2 8 8})\end{array}$ & $\%$ & $\begin{array}{c}\mathrm{N} \\
(\mathbf{7 6 5})\end{array}$ & $\%$ & & \\
\hline \multicolumn{9}{|l|}{ Residence } \\
\hline Rural & 300 & 82.4 & 64 & 17.6 & 364 & 47.6 & 5.93 & \multirow{2}{*}{$0.000 * * *$} \\
\hline Urban & 177 & 44.1 & 224 & 55.9 & 4.1 & 52.4 & $(4.25-8.29)$ & \\
\hline \multicolumn{9}{|l|}{ Maternal education } \\
\hline Illiterate & 28 & 63.6 & 16 & 36.4 & 44 & 5.8 & 1.06 & 0.496 \\
\hline Educated & 449 & 62.3 & 272 & 37.7 & 721 & 94.2 & $(0.56-1.99)$ & \\
\hline \multicolumn{9}{|l|}{ Maternal occupation } \\
\hline Not work & 353 & 61.6 & 220 & 38.4 & 573 & 74.9 & 0.88 & 0.258 \\
\hline Work & 124 & 64.6 & 68 & 35.4 & 192 & 25.1 & $(0.63-1.24)$ & \\
\hline \multicolumn{9}{|l|}{ Social class } \\
\hline Low & 193 & 75.1 & 64 & 24.9 & 257 & 33.6 & 2.38 & \multirow{2}{*}{$0.000 * * *$} \\
\hline Middle \& high & 284 & 55.9 & 224 & 44.1 & 508 & 66.4 & $(1.71-3.32)$ & \\
\hline \multicolumn{9}{|l|}{ Number of visits } \\
\hline $1^{\text {st }}$ visit & 331 & 82.1 & 72 & 17.9 & 403 & 52.7 & 6.81 & \multirow{2}{*}{$0.000 * * *$} \\
\hline Repeated visits & 146 & 40.3 & 216 & 59.7 & 362 & 47.3 & $(4.89-9.46)$ & \\
\hline
\end{tabular}

$* O R=$ Odds Ratio, $\mathrm{CI}=$ Confidence Interval

** Chi-Square Test

$* * *$ Statistically significant 
Table (3): Female satisfaction regarding different components of antenatal care services

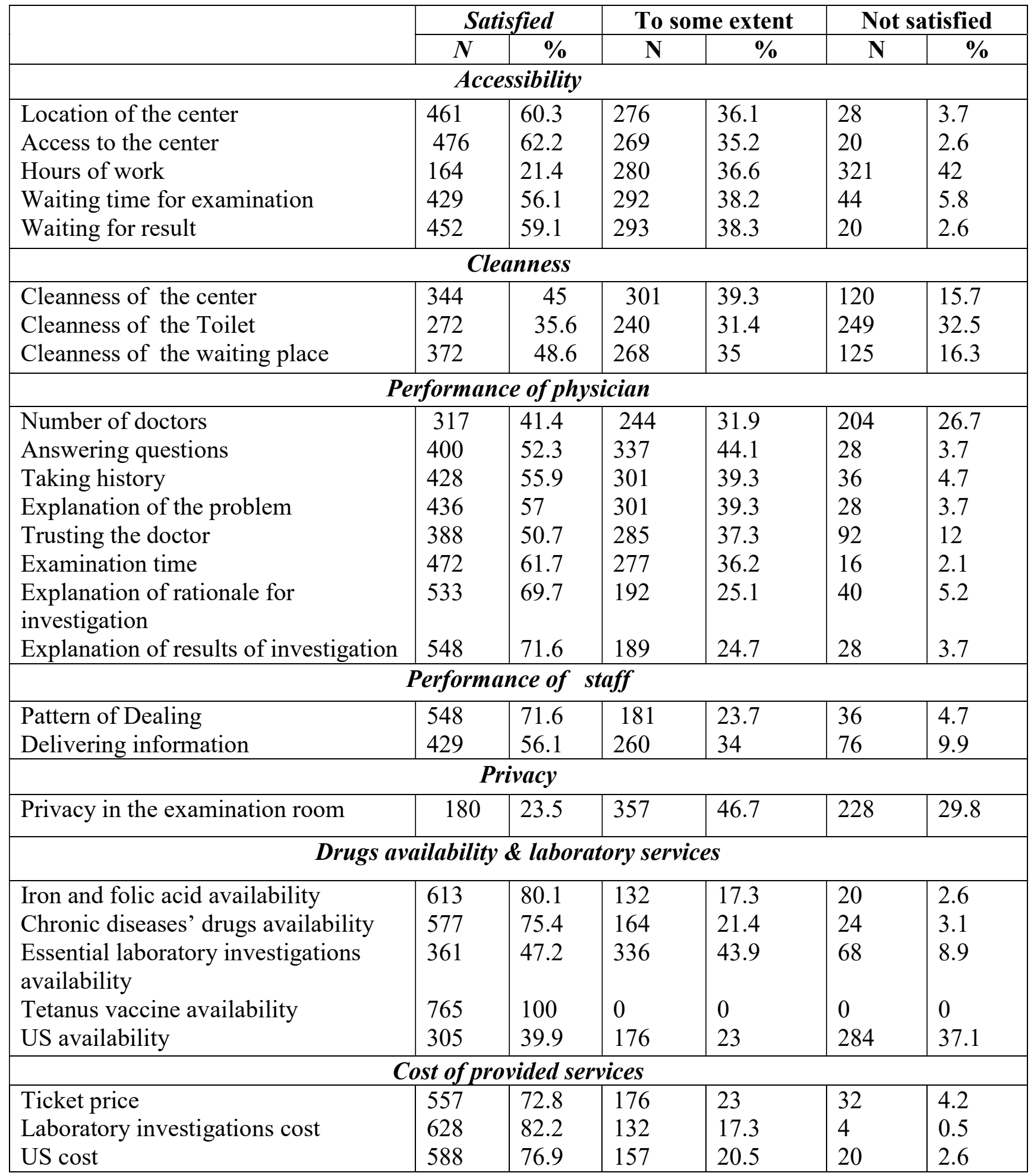


Table (4): Female satisfaction regarding health education sessions and referral system.

\begin{tabular}{|c|c|c|c|c|c|c|}
\hline \multirow[t]{2}{*}{ Health education } & \multicolumn{2}{|c|}{ Satisfied } & \multicolumn{2}{|c|}{ To some extent } & \multicolumn{2}{|c|}{ Not satisfied } \\
\hline & $N$ & $\%$ & $\mathbf{N}$ & $\%$ & $\mathbf{N}$ & $\%$ \\
\hline Antenatal care advantages & 72 & 9.4 & 317 & 41.4 & 376 & 49.2 \\
\hline \multicolumn{7}{|c|}{ Pregnancy care } \\
\hline Physical activity & 24 & 3.1 & 205 & 26.8 & 536 & 70.1 \\
\hline Nutrition & 141 & 18.4 & 244 & 31.9 & 380 & 49.7 \\
\hline Teeth care & 8 & 1 & 88 & 11.5 & 669 & 87.5 \\
\hline Breast care & 141 & 18.4 & 244 & 31.9 & 380 & 49.7 \\
\hline Fetal movements follow up & 269 & 35.2 & 240 & 31.4 & 256 & 33.5 \\
\hline Allowable medication & 176 & 32 & 305 & 39.9 & 284 & 37.1 \\
\hline \multicolumn{7}{|c|}{ At late pregnancy } \\
\hline Signs of labor & 286 & 35 & 185 & 24.2 & 312 & 40.8 \\
\hline Risks during labor & 257 & 33.6 & 244 & 31.9 & 264 & 34.5 \\
\hline \multirow[t]{2}{*}{ Referral services * } & \multicolumn{2}{|c|}{ Satisfied } & \multicolumn{2}{|c|}{ To some extent } & \multicolumn{2}{|c|}{ Not satisfied } \\
\hline & $N$ & $\%$ & $\mathbf{N}$ & $\%$ & $\mathbf{N}$ & $\%$ \\
\hline Explain the cause of referral & 28 & 35 & 36 & 45 & 16 & 20 \\
\hline First aid management & 16 & 20 & 44 & 55 & 20 & 25 \\
\hline Giving full referral report & 16 & 20 & 24 & 30 & 40 & 50 \\
\hline Ambulance availability & 0 & 0 & 0 & 0 & L80 & 100 \\
\hline Help in admission & 0 & 0 & 0 & 0 & 80 & 100 \\
\hline Follow up care & 0 & 0 & 0 & 0 & 80 & 100 \\
\hline
\end{tabular}

*from the studied women only (80) received referral services before. 


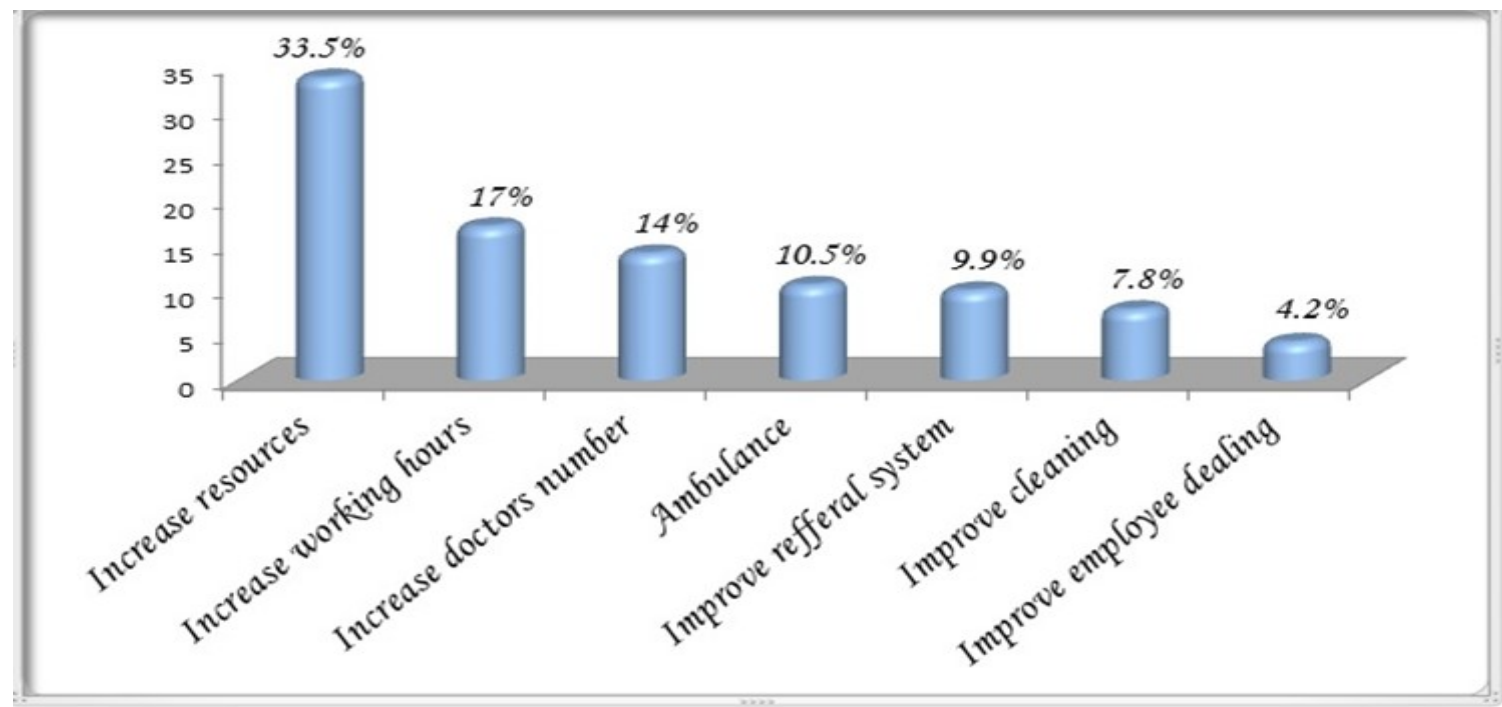

Figure (2): The studied women's recommendations for improving their satisfaction toward the antenatal care service. 
العربى الملخص

خدمات الرعاية الصحية أثناء الحمل ودرجة رضاء العملاء بمحافظة الثرقية ، مصر

ياسمين حسينى حسن حسين ، هناء صلاح سعيد السيد

الخلفية: يعتبر رضاء العميل مقياس لمدى ثقة العملاء بالرعاية الصحية المقدمة، كما يعتبر رضاء السيدات الحوامل مؤشر أداء لتقييم جودة الرعاية أثناء الحمل. الهدف: تقييم رضاء العملاء تجاه الرعاية الصحية المقدمة أثناء الحمل من خلال الرعاية الصحية الأولية بمحافظة الشرقية ، مصر. المنهجية وطرق البحث: أجريت دراسة مقطعية على 765 سيدة حامل ، ومن خلال تقنية أخذ العينات العنقودية متعددة المر احل , تم اختيار أربعة منشآت صحية لتمثل محافظة الثرقية ـ تم جمع بيانات المشاركين فيما يتعلق بالخصائص الاجتماعية و الديمو غر افية ، و عدد زيار اتهم أثناء الحمل وأسئلة لتقييم مدى الرضاء عن جودة الرعاية أثناء الحمل عن طريق استبيان .النتائج : كثنت الدر اسة أنه من بين إجمالي المشاركات ، كان الرضاء بشكل عام عن خدمات الرعاية الصحية اثناء الحمل ( 37.6\%) ـ كان العامل المشترك الذي كان الرضاء عنه بشكل جيد من قبل المشاركين تحديدا هو نوافر لقاح التيتانوس (100 \%) ـ كما كان النقص في متطلبات الإحالة أكثر أسباب عدم الرضاء شيوعًا ـ العملاء الذين كانوا من سكان الحضر، و الذين كانوا من الطبقة الاجتماعية المنوسطة والعالية ومن كانت عدد زيار اتهم أثناء الحمل >2 كانوا الأكثر رضاء عن خدمات الرعاية الصحية المقدمة أثناء الحمل. الخلاصة : تعكس نتائج الدراسة عيوبا متعددة فى المكونات المختلفة لخدمات الرعاية الصحية أثناء الحمل, لذلك يجب اعطاء اهتمام خاص لزيادة الموارد لتحسين جودة خدمات الرعاية الصحية أثناء الحمل فى المحافظة. 